\title{
The relationship between attachment styles and internalizing or externalizing symptoms in clinical and nonclinical adolescents
}

\author{
Fernando Lacasa $^{1 *}$, Merce Mitjavila ${ }^{2}$, Susana Ochoa ${ }^{3}$ and Nekane Balluerka ${ }^{4}$ \\ 1 Psychiatry and Psychology Service. Hospital Sant Joan de Déu of Barcelona. Department of Personality, Evaluation and Psychological Treatment University of Barcelona. \\ 2 Department of Clinical and Health Psychology. University Autonomous of Barcelona. \\ 3 Research Unit. Parc Sanitari Sant Joan de Déu. CIBERS AM. \\ 4 Department of Methodology of the Behavioral Sciences. University of the Basque Country UPV/EHU
}

\begin{abstract}
Título: Relación entre los estilos de apego y los síntomas externalizantes e internalizantes en adolescentes clínicos y no clínicos.

Resumen: Los estudios sobre la relación entre apego y psicopatología durante la adolescencia, se han realizado separadamente en muestras clínicas y no clínicas de adolescentes y han utilizado instrumentos de evaluación diferentes, lo que en conjunto ha podido dar lugar a un sesgo metodológico que ha incrementado la asociación entre apego y psicopatología. Con objeto de evitar este sesgo, en el presente estudio se utilizaron las mismas medidas para explorar la relación entre estilos de apego y síntomas internalizantes y externalizantes en grupos clínicos y no clínicos de adolescentes. La muestra estuvo formada por 248 adolescentes, entre 14 y 18 años de edad. Los adolescentes de cada grupo se emparejaron en edad, sexo y nivel socioeconómico. El apego se valoró con el cuestionario CaMir y los síntomas psicopatológicos con el Youth Self Report. Las relaciones entre apego y psicopatología fueron similares en adolescentes clínicos y no clínicos. El estilo de apego preocupado predijo síntomas internalizantes y externalizantes, quejas somáticas, conducta fóbico-ansiosa, agresividad verbal, conducta de búsqueda de atención y problemas de pensamiento. En comparación con estudios previos, esta investigación ha permitido identificar asociaciones más amplias, más fuertes y más específicas entre el estilo de apego preocupado y los síntomas psicopatológicos en adolescentes.

Palabras clave: Estilo de apego; adolescencia; síntomas internalizantes;
\end{abstract} síntomas externalizantes.

\section{Introduction}

The relationship between insecure attachment and psychopathology has been widely documented in children and adults both concurrently and prospectively (DeKlyen \& Greenberg, 2008; Dozier, Stovall-McClough, \& Albus, 2008), and more recently a number of studies suggest substantial links between adolescent attachment organization and mental health (Allen, 2008). Adolescence is a critical period of psychological adjustment in which individuals develop strategies to regulate their thoughts, feelings, and memories that are related to attachment and based on specific representations and memories of their interactions with past and present attachment figures.

Studies of clinical samples have revealed that $74 \%$ of individuals exhibit insecure attachment, whereas only $42 \%$ of nonclinical subjects display this type of attachment (Bakermans-Kranenburg \& Van Ijzendoorn, 2009). Ward, Lee, and Polan (2006) argued that studies that are performed solely using clinical samples might preferentially include individuals with severe psychopathology, and this could exaggerate the association between attachment and psychopathology. Ward

* Dirección para correspondencia [Correspondence address]:

Fernando Lacasa. Psychiatry and Psychology Service of Hospital Sant Joan Déu of Barcelona. Passeig Sant Joan de Déu, 2. 08950. Esplugues de Llobregat, Barcelona (Spain). E-mail: flacasa@hsjdbcn.org
Abstract: Studies regarding the relationship between attachment and psychopathology during adolescence have been performed separately for clinical and nonclinical adolescents and have used different assessment measures, which together might produce a methodological bias that increases the association between attachment and psychopathology. With the aim of avoiding this bias, the present study used identical measures to explore the relationship between attachment styles and internalizing or externalizing symptoms in clinical and nonclinical samples of adolescents. The sample consisted of 258 adolescents, 129 clinical and 129 nonclinical, aged between 14 and 18 years. The adolescents in each sample were matched for age, gender, and socioeconomic status. Attachment was assessed using the CaMir Q-sort, and psychopathological symptoms were assessed by means of the Youth Self Report (YSR). The relationships between attachment and psychopathology were similar for clinical and nonclinical adolescents. A preoccupied attachment style predicted internalizing and externalizing symptoms, somatic complaints, anxious-fearful behavior, verbal aggression, attention-seeking behavior, and thinking problems. Compared to previous studies, this research has made it possible to identify broader, stronger, and more specific associations between preoccupied attachment style and psychopathological symptoms in adolescents.

Key words: Attachment style; adolescence; internalizing symptoms; externalizing symptoms.

et al. also argued that in cases of severe psychopathology, memories of attachment experiences might be influenced by a hindsight bias. Furthermore, various tools have been used to assess attachment in clinical and nonclinical samples. Ward et al. contended that most attachment and psychopathology studies of clinical adolescents use interviews such as the Adult Attachment Interview (AAI) to assess attachment. In contrast, Shaver and Mikulincer (2002) noted that many of the studies regarding attachment in nonclinical adolescents use self-report questionnaires, although findings obtained with such questionnaires are consistent with findings obtained from transcripts of the AAI. Ward et al., Shaver and Mikulincer and Muris, Meesters, Cor, and van der Berg (2003) recommended studying both clinical and nonclinical samples using the same methods to assess the dynamics of the activation of the attachment system in both samples; however, few studies on attachment and psychopathology in adolescents have followed this recommendation. Our study advances this research field by employing the same assessment tools to analyze the relationship between attachment styles and psychopathological symptoms in both clinical and nonclinical groups.

Studies of adult and adolescent clinical samples support the notion that insecure attachment styles are defensive and predominate in groups of individuals with a history of severe psychiatric problems (Allen, Hauser, \& Borman-Spurrell, 
1996; Dozier, 1990; Rosenstein \& Horowitz, 1996; Wallis \& Steele, 2001). In a meta-analysis of 200 studies of clinical samples, Bakermans-Kranenburg and Van Ijzendoorn (2009) found that those individuals with internalizing disorders (particularly those with a borderline personality disorder) exhibited more concern for past experiences and maximized their attachment needs, including traits that are associated with a preoccupied attachment style. However, individuals with externalizing disorders (particularly those with an antisocial personality disorder) exhibited an avoidant attachment style that avoided past experiences and minimized attachment needs together with a preoccupied attachment style.

Studies of clinical samples of adolescents that have demonstrated relationships between particular attachment styles and specific aspects of psychopathology found that a preoccupied attachment style was associated with depression (Allen et al., 2006; Kobak, Sudler, \& Gamble, 1991; Rosenstein \& Horowitz, 1996), suicidal ideation (Adam, SheldonKeller, \& West, 1996), eating disorders (Miljkovitch, Pierrehumbert, Karmaniola, Bader, \& Halfon, 2005; Pierrehumbert et al., 2002), more interpersonal difficulties, and more overall symptoms than other attachment strategies (Brown \& Wright, 2003), Moreover, an avoidant attachment style has been associated with conduct disorders and drug abuse (Pierrehumbert et al., 2002; Rosenstein \& Horowitz, 1996).

Studies of nonclinical adolescents have also revealed nonspecific relationships between attachment style and psychosocial problems, and both the preoccupied and avoidant attachment styles were associated with internalizing and externalizing problems. Adolescents with an insecure, preoccupied, or avoidant attachment style reported higher levels of anxiety and depression on the Youth Self Report (YSR) (Achenbach, 1991) compared to adolescents with a secure attachment style (Hankin, 2005; Muris \& Meesters, 2002; Muris, Meesters, \& van der Berg, 2003; Nishikawa, Hägglöf, \& Sundbom, 2010; Ronnlund \& Karlsson, 2006). Insecure attachment has also been associated with the YSR scales for internalizing symptoms (Doyle \& Markiewicz, 2005; Muris \& Meesters, 2002; Nishikawa, Hägglöf, \& Sundbom, 2010; Ronnlund \& Karlsson, 2006), somatic complaints, and depression (Muris, Meesters, \& van der Berg, 2003; Ronnlund \& Karlsson, 2006).

Brumariu and Kerns (2010) examined the correlation between attachment and internalizing symptoms, anxiety, and depression in 26 studies of nonclinical preadolescents and adolescents and found that insecure attachment was correlated with symptoms of anxiety and depression more consistently than with general internalizing symptoms; the effect sizes of the correlations between insecure attachment and depressive symptoms ranged from large to extremely large. In a recent meta-analysis of the relationship between attachment and anxiety, Colonnesi et al. (2011) found a large effect size for the association between a preoccupied attachment style and anxiety, and a medium effect size for the relationship between insecure attachment (both avoidant and preoccupied) and anxiety.

Studies of nonclinical samples have not revealed a consistent relationship between attachment and externalizing symptoms. In a sample of 441 adolescents, Muris, Meesters, Morren, and Moorman (2004) found that insecure attachment was correlated with the cognitive and emotional components of aggression, including anger and hostility, but was not correlated with physically and verbally aggressive behavior. Ronnlund and Karlson (2006), Allen, Moore, Kuperminc, and Bell (1998), and Muris et al. (2003) suggested that various aspects of insecure attachment, rather than a particular attachment style, contribute to externalizing symptoms. With respect to this suggestion, Muris et al. (2003) found that parental behavior such as rejection or overprotectionbut not attachment-accounted for some of the variance in the externalizing symptoms of adolescents. Nevertheless, some studies have suggested that preoccupied adolescents are more likely to express externalizing symptoms in certain circumstances, such as when their attachment bids were ignored or rejected by attachment figures (Allen, 2008).

Few studies have investigated both clinical and nonclinical adolescents. Brown and Wright (2003) studied 30 clinical and nonclinical adolescents aged 14 to 20 years and found that adolescents with a preoccupied attachment style had higher scores on the YSR internalizing, depression, and thought problems scales than secure or avoidant adolescents. In other words, compared to studies of nonclinical adolescents, this study found a more specific relationship between internalizing symptoms and preoccupied attachment. Furthermore, gender might also be a factor in the development of psychopathology. In clinical samples, female gender has been associated with a preoccupied attachment style, and male gender has been associated with an avoidant attachment style during adolescence (Lacasa, 2008; Rosenstein \& Horowitz, 1996). Other studies have documented the prevalence of internalizing problems and symptoms in female adolescents and the prevalence of externalizing problems in male adolescents (Abad, Forns, \& Gómez, 2002; Achenbach, 1991; Lemos, Vallejo, \& Sandoval, 2002; Sandoval, Lemos, \& Vallejo, 2006)

However, the relationship between attachment styles and psychopathological symptoms in adolescents has not been clearly established in either clinical or nonclinical samples. To address this issue, the first objective of the present study was to assess the relationship between attachment styles and internalizing and externalizing symptoms in adolescents. Two hypotheses were tested. First, we hypothesized that there is a specific association between a preoccupied attachment style and internalizing symptoms, which is in contrast to the more general relationship between insecure (preoccupied or avoidant) attachment and internalizing symptoms, as other researchers have proposed. Second, in contrast to the findings of other studies, we hypothesized that insecure attachment is associated with externalizing symptoms in adolescents. 
Finally, to test the hypothesis that there is a similar association between attachment style and symptoms in the clinical and nonclinical samples of adolescents, the relationship between attachment styles and psychopathological symptoms was assessed in both groups using the same instruments.

\section{Method}

The present study was a descriptive cross-sectional study with age- and gender-matched case controls.

\section{Participants}

A total of 258 adolescents aged between 14 and 18 years participated in the study. The 129 adolescents in the clinical sample were selected consecutively based upon their participation in group psychotherapy that was conducted at the Child and Adolescent Mental Health Service of the Hospital Sant Joan de Déu located in a town near Barcelona, Catalonia, Spain, from October 2001 through June 2007. The 129 adolescents in the nonclinical sample were recruited from two secondary schools in the same healthcare region and were matched for age, gender, and socioeconomic status (SES) with the adolescents in the clinical sample.

The gross disposable household income (GDHI) per capita (http://www.diba.cat/hg2/sintesi/ sintesi.asp) was used as a reference for measuring the participants' SES. The homogenized average for the GDHI in Catalonia is 100. The families of adolescents living in Cornellà were classified as low SES (GDHI $=80.1)$, the families of adolescents in Esplugues $(G D H I=93.4)$ and Sant Joan Despí $(G D H I=$ 96.5) were classified as middle SES, and the families of adolescents in Sant Just Desvern (GDHI = 138.5) were classified as high SES. Because clinical adolescents resided in each of these municipalities, their families were also low, medium, and high SES. The number of nonclinical adolescents from the middle school in Cornellà was equal to the combined total of clinical adolescents from Cornellà and Esplugues, and the number of nonclinical adolescents from the middle school in Sant Just was equal to the combined total of clinical adolescents from Sant Just and Sant Joan Despí.

Table 1 presents the socio-demographic characteristics of the clinical and non clinical samples.

Table 1. Socio-demographic Characteristics of the Clinical and Nonclinical Samples.

\begin{tabular}{lllll} 
& \multicolumn{2}{l}{ CLINICAL } & \multicolumn{2}{c}{ NONCLINICAL } \\
& $N$ & $\%$ & $N$ & $\%$ \\
\hline Gender & & & & \\
Boys & 55 & $42.6 \%$ & 55 & $42.6 \%$ \\
Girls & 74 & $57.4 \%$ & 74 & $57.4 \%$ \\
Total & 129 & $100 \%$ & 129 & $100 \%$ \\
Socioeconomic Status & & & & \\
Low & 68 & $52.7 \%$ & 101 & $78.3 \%$ \\
Middle-low & 33 & $25.6 \%$ & & \\
Middle-hight & 18 & $14.0 \%$ & & \\
High & 10 & $7.7 \%$ & 28 & $21.7 \%$ \\
Total & 129 & $100 \%$ & 129 & $100 \%$ \\
\hline
\end{tabular}

\section{Procedure}

The adolescents were diagnosed based on interviews by specialists in psychiatry and clinical psychology who used the WHO International Classification of Diseases (ICD-9). The study included adolescents with non-severe psychopathological diagnoses who agreed to participate in the psychotherapy groups. Adolescents who were diagnosed with schizophrenia, psychotic decompensation, anorexia with significant weight loss (loss $>10 \%$ or BMI $<17$ ), manic-depressive psychosis, mental retardation, suicide risk, or who had a primary diagnosis of alcohol or drug abuse were excluded from these psychotherapy groups and therefore were not included in the study. The adolescents primarily visited the mental health center for the mood disorders of anxiety and depression (43.4\%), behavior problems (16.3\%), inhibition $(13.2 \%)$, eating disorders $(8.5 \%)$, or other psychological issues $(20.6 \%)$. The diagnoses included anxiety and phobia disorders $(23.3 \%)$, depressive disorder $(15.5 \%)$, personality disorder $(17.1 \%)$, emotional disorder with onset specific to childhood $(15.5 \%)$, reactive disorder $(8.5 \%)$, conduct disorder and ADHD (8.5\%), eating disorder (8.5\%), and pervasive developmental disorder $(3.1 \%)$.

After the participating adolescents provided informed consent, the assessment measures were performed during two sessions prior to the start of treatment. Participants completed the CaMir Q-sort during the first session and the YSR during the second session. The study complied with the Spanish Psychological Association's ethical standards for human research.

\section{Assessment Instruments}

The CaMir Q-sort (Pierrehumbert et al., 1996), which assumes the existence of a model of the self and the other in interpersonal relationships, is a questionnaire to assess attachment representations in adolescence and adulthood and has been used in many studies to examine the relationship between attachment and psychopathology (Benony, Peny, Gianoli, Hernandez, \& Larome, 2001; Lacasa, 2008; Miljkovitch, Pierrehumbert, Karmaniola, Bader, \& Halfon, 2005; Muela, Torres, \& Balluerka, 2012).

The 72-item CaMir Q-sort assesses secure, avoidant, and preoccupied attachment styles. Based on the CaMir, an individual exhibiting secure attachment values social support and relational security, a person with an avoidant attachment strategy values independence at the expense of social support, whereas a person with a preoccupied strategy values interpersonal involvement at the expense of autonomy (Pierrehumbert et al., 1996; Pierrehumbert et al., 2002). With the CaMir, the subject responds to each item twice. Initially, the participant distributes 72 cards freely into five piles based on a Likert-type scale ranging from "strongly agree" to "strongly disagree". The participants then respond to the items a second time, and these responses must conform to a "forced distribution" that limits each pile to a specific num- 
ber of cards. The second distribution is used to calculate the attachment style. The Q-sort responses that are obtained for each participant are correlated with the three prototypes corresponding to the secure, avoidant, and preoccupied attachment styles and provide three correlation coefficients ( $Q$ indexes) that reflect the similarity of the individual's answer to each of the three types of attachment (Pierrehumbert et al., 2002).

The Spanish adaptation of the original instrument has shown adequate validity and reliability (Lacasa, 2008; Muela, 2011). In this Spanish version, the values of the intraclass correlation between the 6 judges who designed the Spanish Camir profiles were: $0.942(p<.0001)$ for the Secure profile, $0.962(p<.0001)$ for the Avoidant profile, and $0.920(p<$ .0001) for the Preoccupied profile. With regard to test-retest reliability, it was explored in a sample of 62 participants aged between 14 and 18 years (Mean $=15.8, S D=1.22$ ), who answered the questionnaire twice with a time interval of 4 weeks between both answers. The correlation coefficients between the two administrations were $0.761(p<.0001)$ for the Secure style, $0.627(p<.0001)$ for the Avoidant style, and $0.698(p<.0001)$ for the Preoccupied style.

The Youth Self-Report (YSR) (Achenbach, 1991) is a self-report measure of psychopathological behavior in adolescents from 11 to 18 years of age. The 112-item YSR assesses a wide range of behavioral and emotional problems and is based on the adolescent's report of the extent to which each item statement reflects how he or she has felt or has acted in the past six months. The YSR has been translated into more than 60 languages and is widely used in clinical practice and research. The YSR provides a quantitative and numerical taxonomy that consists of the following set of narrowly defined syndromes that are empirically derived through factor analysis: depression, verbal aggression, delinquent behavior, thought problems, somatic complaints, and the social problems of isolation, attention seeking, and anx- ious-fearful behavior (Lemos, Vallejo, \& Sandoval, 2002). The YSR also includes the two higher-order psychopathology factors of internalizing and externalizing symptoms. The most recent Spanish standardization was used in the present study (Sandoval, Lemos, \& Vallejo, 2006).

\section{Data Analysis}

We used the SPSS 20.0 software program to analyze the data. The Student's $t$-test was used to compare the differences between the means of the clinical and nonclinical samples for the categories of psychopathology; Cohen's $d$ was also calculated to provide an index of effect size.

To analyze whether attachment style, gender, age or clinical diagnosis predicted psychopathological symptoms, several multiple regression analyses were performed using the step-by-step method. For each of the analyses, one of the behavioral and emotional problems that were identified by the YSR served as the dependent variable, and attachment style, gender, age and sample (nonclinical or clinical) served as the predictor variables.

One-way ANOVAs were performed to determine whether the psychopathological symptoms differed as a function of attachment style; post-hoc pairwise comparisons between the three attachment strategies were performed using Tukey test and Hedges' $g$ index was calculated to provide the effect size for each comparison.

\section{Results}

\section{Attachment Style, and Clinical Symptoms of the Sample}

Table 2 presents the attachment styles, and clinical symptoms of the clinical and nonclinical adolescent samples.

Table 2. Attachment and Clinical Characteristics of the Clinical and Nonclinical Samples.

\begin{tabular}{|c|c|c|c|c|c|c|c|}
\hline & \multicolumn{2}{|c|}{ CLINICAL } & \multicolumn{2}{|c|}{ NONCLINICAL } & & & \\
\hline \multicolumn{8}{|l|}{ Attachment Style } \\
\hline Secure & 23 & $20.2 \%$ & 72 & $67.3 \%$ & & & \\
\hline Avoidant & 38 & $33.3 \%$ & 23 & $21.5 \%$ & & & \\
\hline Preoccupied & 53 & $46.5 \%$ & 12 & $11.2 \%$ & & & \\
\hline Total & 114 & $100 \%$ & 107 & $100 \%$ & & & \\
\hline & $M$ & $(S D)$ & $M$ & $(S D)$ & Student's $t$ & Sig. (two-tailed) & Cohen's $d$ \\
\hline Age & 15.71 & $(0.97)$ & 15.71 & $(0.97)$ & & & \\
\hline \multicolumn{8}{|c|}{ Symptoms (Youth Self Report) } \\
\hline Total Symptoms & 66.06 & $(18.72)$ & 38.91 & $(18.83)$ & 9 & .001 & 1.24 \\
\hline Internalizing Symptoms & 16.65 & $(6.57)$ & 9.24 & $(5.63)$ & 8.49 & .001 & 1.14 \\
\hline Externalizing Symptoms & 10.85 & $(4.90)$ & 6.79 & $(4.04)$ & 6.57 & .001 & 0.88 \\
\hline Depression & 6.17 & $(3.80)$ & 2.82 & $(2.82)$ & 7.24 & .001 & 0.98 \\
\hline Delinquent Behavior & 2.37 & $(2.38)$ & 1.11 & $(1.79)$ & 4.37 & .001 & 0.59 \\
\hline Verbal Aggression & 5.96 & $(2.76)$ & 4.30 & $(2.58)$ & 4.62 & .001 & 0.62 \\
\hline Thought Problems & 2.33 & $(2.15)$ & 1.52 & $(2.03)$ & 2.88 & .004 & 0.38 \\
\hline Somatic Complaints & 2.86 & $(2.12)$ & 1.54 & $(1.57)$ & 4.89 & .001 & 0.65 \\
\hline Social Problems & 3.75 & $(1.99)$ & 2.99 & $(1.80)$ & 2.95 & .003 & 0.39 \\
\hline Attention Seeking & 2.52 & $(1.52)$ & 1.44 & $(1.34)$ & 5.59 & .001 & 0.75 \\
\hline Anxious-Fearful Behavior & 3.81 & $(1.67)$ & 2.19 & $(1.83)$ & 6.73 & .001 & 0.90 \\
\hline
\end{tabular}


In the clinical group, $79.8 \%$ of the adolescents exhibited an insecure attachment style, and $20.2 \%$ displayed a secure attachment style; in the nonclinical sample, $32.7 \%$ of the adolescents exhibited an insecure attachment style, and 67.3\% displayed a secure attachment style.

As expected, the adolescents in the clinical sample had higher scores for all of the symptoms as assessed by the YSR compared to the nonclinical adolescents. The effect sizes for the mean differences between the clinical and nonclinical adolescents were large for depression, anxious-fearful behavior, and internalizing and externalizing symptoms; the effect sizes were moderate for delinquent behavior, verbal aggression, somatic complaints and attention seeking; and the effect sizes were smaller for group differences in thought problems and social problems.

\section{Predicting Psychopathology Risk from Attachment Style}

When assessing the risk of psychopathology based on the three attachment styles, a preoccupied attachment style was a significant predictive factor for eight of the ten YSR factor scores and accounted for $12 \%$ of the total YSR symptoms and problems score (see Table 3).

Preoccupied attachment style, clinical status, and female gender explained $47 \%$ of the variance in the total symptoms and problems YSR score, $44 \%$ of the variance in the internalizing score, and $19 \%$ of the variance in the somatic complaints score. A preoccupied attachment style and clinical status explained $20 \%$ of the variance in the externalizing YSR score, $11 \%$ of the variance in the verbal aggression score, $12 \%$ in the attention seeking score, and $17 \%$ of the variance in the anxious-fearful behavior score. A preoccupied attachment style accounted for $13 \%$ of the variance in the YSR thought problems score and $6 \%$ in the social problems score. An insecure attachment style, clinical status, and male gender explained $16 \%$ of the variance in the YSR delinquent behavior score; an insecure attachment style, female gender, age, and clinical status explained $44 \%$ of the YSR depression score.

Table 3. Multiple Linear Regression Analysis of Youth Self Report (YSR) Symptom Scores, with Q Scores, Sample, Gender and Age as Predictors.

\begin{tabular}{|c|c|c|c|c|c|}
\hline \multirow[t]{2}{*}{ Dependent Variable } & \multicolumn{5}{|l|}{ Predictive Variables } \\
\hline & $N=258$ & $\beta$ & $R^{2}$ & $\Delta R^{2}$ & Sig. \\
\hline \multirow{3}{*}{ Total Problems and Symptoms } & Sample (0:Nonclinical; 1:Clinical) & 25.87 & 0.31 & 0.31 & .001 \\
\hline & Q_Preoccupied & 0.65 & 0.43 & 0.12 & .001 \\
\hline & Gender (0:Boys; 1: Girls) & 9.99 & 0.47 & 0.04 & .001 \\
\hline \multirow{4}{*}{ Internalizing } & Q_Preoccupied & 0.28 & 0.27 & 0.27 & .001 \\
\hline & Sample (0:Nonclinical; 1:Clinical) & 4.99 & 0.38 & 0.11 & .001 \\
\hline & Gender (0:Boys; 1: Girls) & 3.57 & 0.44 & 0.06 & .001 \\
\hline & SES (0:Low; 1: High) & -1.9 & 0.45 & 0.01 & .05 \\
\hline \multirow{2}{*}{ Externalizing } & Sample (0:Nonclinical; 1:Clinical) & 3.76 & 0.15 & 0.15 & .001 \\
\hline & Q_Preoccupied & 0.09 & 0.20 & 0.05 & .001 \\
\hline \multirow{4}{*}{ Depression } & Q_Secure & -0.16 & 0.26 & 0.26 & .001 \\
\hline & Gender (0:Boys; 1: Girls) & 2.33 & 0.35 & 0.09 & .001 \\
\hline & Sample (0:Nonclinical; 1 :Clinical) & 2.32 & 0.43 & 0.08 & .001 \\
\hline & Age $(14,15,16,17$ and 18 years $)$ & 0.42 & 0.44 & 0.01 & .032 \\
\hline \multirow{3}{*}{ Delinquent Behavior } & Q_Secure & -0.06 & 0.10 & 0.10 & .001 \\
\hline & Gender (0:Boys; 1: Girls) & -0.83 & 0.14 & 0.03 & .005 \\
\hline & Sample (0:Nonclinical; 1 :Clinical) & 0.67 & 0.16 & 0.02 & .033 \\
\hline \multirow{2}{*}{ Verbal Aggression } & Q_Preoccupied & 0.06 & 0.08 & 0.08 & .001 \\
\hline & Sample (0:Nonclinical; 1 :Clinical) & 1.03 & 0.11 & 0.03 & .011 \\
\hline Thought Problems & Q_Preoccupied & 0.06 & 0.13 & 0.13 & .001 \\
\hline \multirow{4}{*}{ Somatic Complaints } & Q_Preoccupied & 0.05 & 0.11 & 0.11 & .001 \\
\hline & Gender (0:Boys; 1 : Girls) & 0.93 & 0.16 & 0.06 & .001 \\
\hline & SES (0:Low; 1: High) & -0.95 & 0.19 & 0.03 & .002 \\
\hline & Sample (0:Nonclinical; 1 :Clinical) & 0.84 & 0.24 & 0.05 & .003 \\
\hline \multirow{2}{*}{ Social Problems } & Q_Preoccupied & 0.04 & 0.06 & 0.06 & .001 \\
\hline & SES (0:Low; 1: High) & -0.67 & 0.08 & 0.02 & .05 \\
\hline \multirow{2}{*}{ Attention Seeking } & Sample (0:Nonclinical; 1:Clinical) & 0.98 & 0.10 & 0.10 & .001 \\
\hline & Q_Preoccupied & 0.02 & 0.12 & 0.02 & .035 \\
\hline \multirow{2}{*}{ Anxious-Fearful Behavior } & Sample (0:Nonclinical; 1:Clinical) & 1.49 & 0.15 & 0.15 & .001 \\
\hline & Q_Preoccupied & 0.03 & 0.17 & 0.03 & .010 \\
\hline
\end{tabular}


The Relationship between Attachment Style and Psychopathological Symptoms in the Clinical and Nonclinical Samples

The associations between attachment styles and YSR symptom scores were determined for the clinical and nonclinical adolescent groups using the same measurement instrument (see Table 4 and Table 5). In both groups, relative to the adolescents with a secure attachment style, the adolescents who exhibited a preoccupied attachment style scored significantly higher on internalizing symptoms $(p<.001$, Hedges' $g=1.33$ for the clinical sample; $p<.05$, Hedges' $g=$ 0.97 for the nonclinical sample); depression $(p<.001$, Hedges' $g=1.22$ for both samples); thought problems $(p<$ .01 , Hedges' $g=0.87$ for the clinical sample; $p<.01$, Hedges' $g=1.06$ for the nonclinical sample); and total symptoms $(p<.001$, Hedges' $g=1.52$ for the clinical sample; $p<.01$, Hedge's $g=1.32$ for the nonclinical sample). In both groups, the adolescents with a preoccupied attachment style had higher scores on depression than the adolescents with an avoidant style $(p<.01$, Hedges' $g=0.77$ for the clinical sample; $p<.05$, Hedges' $g=0.96$ for the nonclinical sample).

In the nonclinical group, the adolescents with a preoccupied attachment style showed higher scores on internalizing behavior than the adolescents with an avoidant style $(p<$ .05 , Hedges' $g=1.17$ ). This difference was smaller in the clinical group (Hedges' $g=0.63$ ). The adolescents in the nonclinical sample with a preoccupied attachment style had higher scores than the adolescents with a secure style on externalizing symptoms $(p<.05$, Hedges' $g=0.88)$, and on attention seeking $(p<.05$; Hedges ' $g=0.85)$. In this sample, the adolescents with an avoidant attachment style showed higher scores on delinquent behavior than the adolescents with a secure style $(p<.05$, Hedges' $g=0.58)$.

In the clinical sample, the adolescents with a secure style had smaller scores than the adolescents with a preoccupied style $(p<.05$, Hedges' $g=0.77)$ and than the adolescents with an avoidant style $(p<.01$, Hedges' $g=0.9)$ on social problems. Finally, the adolescents with a preoccupied style showed higher scores than the adolescents with an avoidant style $(p<.01$, Hedges' $g=0.74)$ on verbal aggression.

Table 4. Differences on the Youth Self Report according to Attachment Styles in the Clinical Sample.

\begin{tabular}{|c|c|c|c|c|c|c|c|c|c|c|}
\hline \multirow{2}{*}{$\begin{array}{l}\text { Youth Self } \\
\text { Report }\end{array}$} & \multicolumn{3}{|l|}{ Attachment } & \multicolumn{2}{|c|}{ Anova } & \multirow{2}{*}{\multicolumn{3}{|c|}{ Post-hoc Tukey Contrasts }} & \multirow{2}{*}{ [1] } & \multirow[t]{2}{*}{ Hedges' 8} \\
\hline & Styles & M & $S D$ & $F$ & [1] & & & & & \\
\hline \multirow{3}{*}{ Total Problems and Symptoms } & Secure & 52.13 & 16.4 & \multirow{3}{*}{11.95} & \multirow{3}{*}{$* * *$} & Secure & $<$ & Preoccupied & $* * *$ & 1.52 \\
\hline & Avoidant & 64.08 & 19.49 & & & \multirow[t]{2}{*}{ Avoidant } & \multirow[t]{2}{*}{$<$} & \multirow{2}{*}{ Preoccupied } & \multirow[t]{2}{*}{$*$} & \multirow[t]{2}{*}{0.68} \\
\hline & Preoccupied & 76.69 & 13.28 & & & & & & & \\
\hline \multirow{3}{*}{ Internalizing Behavior } & Secure & 12.06 & 6.05 & \multirow{3}{*}{10.35} & \multirow{3}{*}{$* * *$} & \multirow[t]{3}{*}{ Secure } & \multirow[t]{3}{*}{$<$} & \multirow[t]{3}{*}{ Preoccupied } & \multirow[t]{3}{*}{$* * *$} & \multirow[t]{3}{*}{1.33} \\
\hline & Avoidant & 16.16 & 6.52 & & & & & & & \\
\hline & Preoccupied & 19.85 & 5.21 & & & & & & & \\
\hline \multirow{3}{*}{ Depression } & Secure & 4.1 & 2.83 & \multirow{3}{*}{10.02} & \multirow{3}{*}{$* * *$} & Secure & $<$ & Preoccupied & $* * *$ & 1.22 \\
\hline & Avoidant & 5.33 & 3.92 & & & \multirow{2}{*}{ Avoidant } & $<$ & Preoccupied & $* *$ & 0.77 \\
\hline & Preoccupied & 8.02 & 3.49 & & & & & & & \\
\hline & Secure & 1.15 & 1.35 & & & Secure & $<$ & Preoccupied & $* *$ & 0.87 \\
\hline Thought Problems & Avoidant & 2.45 & 2.47 & 5.14 & $* *$ & & & & & \\
\hline & Preoccupied & 2.95 & 2.05 & & & & & & & \\
\hline & Secure & 2.55 & 1.73 & & & Secure & $<$ & Avoidant & $* *$ & 0.9 \\
\hline Social Problems & Avoidant & 4.27 & 2.21 & 5.44 & $* *$ & & & & & \\
\hline & Preoccupied & 4.02 & 1.75 & & & Secure & $<$ & Preoccupied & * & 0.77 \\
\hline & Secure & 2.35 & 2.45 & & & & & & & \\
\hline Somatic Complaints & Avoidant & 2.65 & 2.17 & 1.61 & ns & & & & & \\
\hline & Preoccupied & 3.35 & 1.87 & & & & & & & \\
\hline & Secure & 3.3 & 1.53 & & & & & & & \\
\hline Anxious Fearful & Avoidant & 3.69 & 1.39 & 1.97 & ns & & & & & \\
\hline & Preoccupied & 4.18 & 1.9 & & & & & & & \\
\hline & Secure & 9.1 & 3.68 & & & & & & & \\
\hline Externalizing & Avoidant & 10.5 & 5.3 & 2.85 & ns & & & & & \\
\hline & Preoccupied & 12.13 & 4.96 & & & & & & & \\
\hline & Secure & 1.3 & 1.34 & & & & & & & \\
\hline Delinquent Behavior & Avoidant & 2.83 & 2.42 & 2.86 & ns & & & & & \\
\hline & Preoccupied & 2.6 & 2.63 & & & & & & & \\
\hline & Secure & 5.7 & 2.79 & & & & & & & \\
\hline Verbal Aggression & Avoidant & 4.93 & 2.53 & 4.9 & $* *$ & Avoidant & $<$ & Preoccupied & $* *$ & 0.74 \\
\hline & Preoccupied & 6.89 & 2.69 & & & & & & & \\
\hline & Secure & 2.1 & 1.33 & & & & & & & \\
\hline Attention Seeking & Avoidant & 2.73 & 1.51 & 1.15 & $n s$ & & & & & \\
\hline 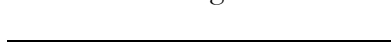 & Preoccupied & 2.64 & 1.64 & & & & & & & \\
\hline
\end{tabular}

[1] Two-tailed significance: $* p<.05 ; * * p<.01 ; * * * p<.001$ 
Table 5. Differences on the Youth Self Report according to Attachment Styles in the Nonclinical Sample.

\begin{tabular}{|c|c|c|c|c|c|c|c|c|c|c|}
\hline \multirow[t]{2}{*}{ Youth Self Report } & \multicolumn{3}{|l|}{ Attachment } & \multicolumn{2}{|c|}{ Anova } & \multicolumn{4}{|c|}{ Post-hoc Tukey Contrasts } & \multirow[t]{2}{*}{ Hedges' $g$} \\
\hline & Styles & $M$ & $S D$ & $F$ & {$[1]$} & & & & {$[1]$} & \\
\hline \multirow{3}{*}{ Total Problems and Symptoms } & Secure & 37.57 & 17.64 & \multirow{3}{*}{6.15} & \multirow{3}{*}{$* *$} & \multirow{3}{*}{$\begin{array}{l}\text { Secure } \\
\text { Avoidant }\end{array}$} & \multirow{3}{*}{$\begin{array}{l}< \\
<\end{array}$} & \multirow{3}{*}{$\begin{array}{l}\text { Preoccupied } \\
\text { Preoccupied }\end{array}$} & \multirow{3}{*}{ ** } & \multirow{3}{*}{$\begin{array}{l}1.32 \\
1.14\end{array}$} \\
\hline & Avoidant & 40.69 & 17.14 & & & & & & & \\
\hline & Preoccupied & 60.63 & 16.79 & & & & & & & \\
\hline \multirow{3}{*}{ Internalizing Behavior } & Secure & 9.45 & 5.35 & \multirow{3}{*}{4.47} & \multirow{3}{*}{$*$} & Secure & $<$ & Preoccupied & * & 0.97 \\
\hline & Avoidant & 8.39 & 4.45 & & & & & & & \\
\hline & Preoccupied & 14.67 & 7.02 & & & Avoidant & $<$ & Preoccupied & * & 1.17 \\
\hline \multirow{3}{*}{ Depression } & Secure & 2.42 & 2.4 & \multirow{3}{*}{7.62} & \multirow{3}{*}{$* * *$} & Secure & $<$ & Preoccupied & $* * *$ & 1.22 \\
\hline & Avoidant & 3.09 & 2.27 & & & Avoidant & $<$ & Preoccupied & $*$ & 0.96 \\
\hline & Preoccupied & 5.67 & 4.38 & & & & & & & \\
\hline \multirow{3}{*}{ Thought Problems } & Secure & 1.32 & 1.82 & \multirow{3}{*}{5.03} & \multirow{3}{*}{$* *$} & Secure & $<$ & Preoccupied & $* *$ & 1.06 \\
\hline & Avoidant & 1.82 & 1.99 & & & & & & & \\
\hline & Preoccupied & 3.4 & 2.8 & & & & & & & \\
\hline \multirow{3}{*}{ Social Problems } & Secure & 3.03 & 1.79 & \multirow{3}{*}{0.26} & \multirow{3}{*}{ ns } & & & & & \\
\hline & Avoidant & 2.81 & 1.83 & & & & & & & \\
\hline & Preoccupied & 3.27 & 1.27 & & & & & & & \\
\hline \multirow{3}{*}{ Somatic Complaints } & Secure & 1.76 & 1.51 & & & & & & & \\
\hline & Avoidant & 1.14 & 1.11 & 3.04 & ns & & & & & \\
\hline & Preoccupied & 2.6 & 2.55 & & & & & & & \\
\hline & Secure & 2.3 & 1.88 & & & & & & & \\
\hline Anxious Fearful & Avoidant & 1.91 & 1.83 & 2.01 & ns & & & & & \\
\hline & Preoccupied & 3.25 & 1.96 & & & & & & & \\
\hline & Secure & 6.59 & 3.67 & & & Secure & $<$ & Preoccupied & $*$ & 0.88 \\
\hline Externalizing & Avoidant & 7.81 & 4.92 & 3.71 & $*$ & & & & & \\
\hline & Preoccupied & 10 & 2.87 & & & & & & & \\
\hline & Secure & 0.86 & 1.27 & & & Secure & $<$ & Avoidant & $*$ & 0.58 \\
\hline Delinquent Behavior & Avoidant & 1.91 & 2.97 & 3.79 & $*$ & & & & & \\
\hline & Preoccupied & 1.83 & 1.64 & & & & & & & \\
\hline & Secure & 4.29 & 2.41 & & & & & & & \\
\hline Verbal Aggression & Avoidant & 4.95 & 2.95 & 1.41 & ns & & & & & \\
\hline & Preoccupied & 5.5 & 1.9 & & & & & & & \\
\hline & Secure & 1.44 & 1.24 & & & Secure & $<$ & Preoccupied & $*$ & 0.85 \\
\hline Attention Seeking & Avoidant & 1.64 & 1.43 & 3.39 & $*$ & & & & & \\
\hline & Preoccupied & 2.55 & 1.57 & & & & & & & \\
\hline
\end{tabular}

\section{Discussion}

The results obtained supported the hypotheses of this study. Most of the internalizing symptoms were associated with a preoccupied attachment style, and most of the externalizing symptoms were also associated with a preoccupied style rather than with insecure attachment in general. Finally, the study results indicate that the associations between attachment and symptoms of psychopathology were similar for the clinical and nonclinical adolescent samples.

As we hypothesized, in the YSR, a preoccupied attachment style was associated with scores for internalizing symptoms. This result confirms similar findings by Brown et al. (2003) and is more specific than the results that were obtained by either Brumariu and Kerns (2010), Ronnlund and Karlsson (2006), or Muris et al. (2000; 2001; 2002), who found that internalizing symptoms were related to insecure attachment in general. In the present study, internalizing symptoms were related primarily to the preoccupied attachment style. In our study, the preoccupied attachment style explained $27 \%$ of the variance in internalizing symptoms. In nonclinical samples, Allen, Moore, Kuperminc, and Bell (1998) found that a preoccupied attachment style explained $8 \%$ of the variance in internalizing symptoms, and Muris et al. (2003) found that the association between insecure attachment and internalizing symptoms on the YSR in adolescents exhibited a moderate effect size. In a review, Brumariu et al. (2010) reported that studies using different instruments found that insecure attachment was related to internalizing symptoms, with effect sizes that range from medium to large. The present study found a strong association (i.e., a large effect size) between a preoccupied attachment style and internalizing symptoms.

Muris et al. (2003) found that somatic complaints were related to insecure attachment. The findings of the present study were more specific and revealed that the preoccupied attachment style explained $11 \%$ of the variance in somatic complaints. Similarly, Muris et al. (2000; 2001; 2002) found that anxiety problems were associated generally with insecure attachment; in the present study, anxious-fearful behavior was related specifically to the preoccupied attachment 
style, and this finding is consistent with the results that were obtained by Brown et al. (2003) and Colonnesi et al. (2011).

The preoccupied attachment style involves hyperactivation of negative emotions and feelings (Shaver \& Mikulincer, 2002) and internalizing symptoms and problems in general -and anxiety problems and somatic complaints in particular- may be the result of this type of emotional regulation. Adolescents with a preoccupied attachment style may remain hypervigilant toward their attachment figures and exaggerate their emotions in an attempt to attract the attention of a caretaker that is sensitive only sporadically. Similarly, distress signals that are specific to internalizing problems may serve an attachment function by attracting an inconsistent protective figure. The expression of internalizing symptoms, soma-tic complaints, and anxious-fearful behavior may be a type of attachment behavior, as it attempts to elicit a protective, caretaking activity from the caregiver (Allen, Moore, Kuperminc, \& Bell, 1998; Dozier \& Lee, 1995; Kobak, Cole, Ferenz-Gillies, Fleming, \& Gamble, 1993)

The study findings failed to support the hypothesis of an association between insecure attachment and externalizing symptoms (Allen, Moore, Kuperminc, \& Bell, 1998; Ronnlund \& Karlsson, 2006). However, the analysis did reveal a specific relationship between a preoccupied attachment style and externalizing symptoms as well as an association between a preoccupied attachment style, attention seeking, and verbal aggression. Externalizing symptoms may attract the attention of attachment figures and increase the intensity — albeit negatively — of attachment relationships (Allen, 2008). An adolescent with a preoccupied attachment style may use behavior problems as an extreme and ambivalent way of obtaining a caregiver's response. Similar to the way that a stubborn child might use anger to provoke the attention of the caregiver, an adolescent with a preoccupied attachment style might engage in hostile, exasperating, or even self-destructive behavior to garner parental attention while simultaneously expressing anxiety and resistance. Interactions with parents can be characterized as frequent, intense arguments that involve a loss of boundaries, verbal threats, and the eruption of conflicts that are difficult to resolve. To maintain the closeness and physical presence of attachment figures, these adolescents may use verbal aggression and arguments. Moreover, because preoccupied adolescents often find it difficult to obtain independence from their parents, these behaviors might be borne out of frustration in a misguided attempt to achieve autonomy.

The preoccupied attachment style also predicted thought problems, and this prediction is consistent with findings that were obtained by Brown et al. (2003) and Ronnlund et al. (2006). Individuals with a preoccupied attachment style might suffer from thought problems because they tend to excessively focus on and worry about their own thoughts and feelings (Dozier, Stovall-McClough, \& Albus, 2008; Rosenstein \& Horowitz, 1996), which can serve as an additional source of stress.
Insecure attachment accounted for $26 \%$ of the variance in depression symptoms on the YSR. This result is similar to the findings of Miljkovitch et al. (2005), Muris et al. (2000; 2001), Allen et al. (2006), Brumariu et al. (2010) and Mikulincer and Shaver (2007). Miljkovitch et al., who used the CaMir Q-sort to assess both types of insecure attachment (preoccupied and avoidant) in a nonclinical sample, found that it accounted for $48 \%$ of the variance in depression. Mikulincer and Shaver found that both types of insecure attachment predisposed individuals to experience depressive symptoms, although the two types of attachments differed in the ways in which they contributed to depression. The preoccupied attachment style was correlated with interpersonal aspects of depression, whereas the overdependence and lack of autonomy that are associated with this type of attachment render individuals vulnerable to feelings of rejection and abandonment. In contrast, avoidant attachment was correlated with the aspects of depression that are related to failure, although the compulsive self-importance of individuals with an avoidant attachment style was associated with perfectionism, self-punishment, and self-criticism.

To a certain extent, insecure attachment was associated with delinquent behavior. Previous studies found that both the preoccupied (Allen et al., 2002; Allen, Moore, Kuperminc, \& Bell, 1998) and avoidant attachment (Rosenstein \& Horowitz, 1996) styles were related to delinquent behavior in adolescents. Insecure attachment was also correlated with angry feelings and hostile thoughts, but not with physical or verbal aggression (Muris, Meesters, Morren, \& Moorman, 2004). The results of the present study are consistent with those findings, and the various styles of insecure attachment may contribute to the adolescent's delinquent behavior in different ways. Adolescents with a preoccupied attachment style might exhibit behavior and delinquency problems to attract attention and care from their attachment figures. In contrast, adolescents with an avoidant attachment style might exhibit antisocial behavior to diminish the importance of attachment relationships and to distance themselves from parents who do not respond to their attachment needs (Mikulincer \& Shaver, 2007). Clinical status and male gender also predicted delinquent behavior, albeit to a lesser extent, and other studies have described the combined factors of male gender, clinical status, and an avoidant attachment style as contributing to the development of delinquent behavior in adolescents (Rosenstein \& Horowitz, 1996).

In the present study, female gender predicted depression, somatic complaints, and internalizing symptoms, whereas male gender predicted delinquent behavior. These findings are consistent with previous studies in which female and male gender were associated with a higher prevalence of internalizing and externalizing problems, respectively (Abad, Forns, \& Gómez, 2002; Achenbach, 1991; Allen, Moore, Kuperminc, \& Bell, 1998; Lemos, Vallejo, \& Sandoval, 2002; Muris, Meesters, \& van der Berg, 2003; Rosenstein \& Horowitz, 1996; Sandoval, Lemos, \& Vallejo, 2006; Zubeidat, Fernández, Ortega, Vallejo, \& Sierra, 2009). 
However, although an increase in symptoms between the ages of 14 and 18 has been previously reported for Spanish adolescents (Sandoval, Lemos, \& Vallejo, 2006; Zubeidat, Fernández, Ortega, Vallejo, \& Sierra, 2009), the present study found that age only accounted for $1 \%$ of the variance in depression, and it did not relate to any other symptom.

Clinical status was another predictive variable. As expected, the clinical adolescents exhibited higher scores on all of the evaluated symptoms and exhibited more insecure attachment compared to the nonclinical adolescents. However, although the intensity of the symptoms could be different between the clinical and nonclinical adolescents, we expected the pattern of relationships between the attachment and psychopathological symptoms to be similar in both samples. We have partially confirmed this prediction. As expected, the same relationship between attachment and psychopathology was found in clinical and non clinical adolescents for total problems and symptoms, internalizing symptoms, depression and thought problems, but not for the other symptoms.

Our study partially refutes the assertion of Ward et al. (2006) that in studies focused on the relationship between attachment and psychopathological symptoms performed on samples with severe pathology, such relationship is usually exaggerated. In fact, employing the same assessment tools to analyze this relationship in both clinical and nonclinical groups, we have observed a strong relationship between some symptoms and the attachment styles in both samples. Therefore, for those symptoms, that relationship does not depend on the sample characteristics.

In both groups the adolescents with a preoccupied attachment style scored higher than the adolescents with a secure style in internalizing symptoms, depression, thought problems, and the total problems and symptoms. Moreover, adolescents with a preoccupied attachment style also scored higher than avoidant adolescents in depression and total symptoms.

These results are compatible with the assertion of Mikulincer and Shaver (2007), that some disorders can be more closely related than others with a dysfunction of the attachment system. And this dysfunction of attachment system, at the emotional, cognitive or interpersonal level, can render a person vulnerable to serious mental disorders. However, in other disorders, the insecurity of attachment does not seem to be enough to cause a mental disorder, but seems to act as a 'catalyst' of other pathologic processes by reducing psychological and social resources, and weakening a person's resilience (Mikulincer \& Shaver, 2007). Accordingly, we do not consider that the relationship between the attachment and psychopathology is exaggerated as Ward et al. (2006) assert, but we feel that the attachment style may act with other risk factors in a more direct or indirect way to produce a maladjustment.

\section{Conclusion}

The similarities that were observed in clinical and nonclinical adolescents in the relationship between attachment and the psychopathological symptoms do not support Ward's (2006) claim that the relationship between attachment and psychopathology has been exaggerated due to studies of attachment and psychopathology being restricted to clinical samples of adults and adolescents.

Compared to previous studies, assessing attachment strategies with a continuous measure - i.e., the CaMir Qsort - made it possible to identify broader, stronger, and more specific associations between attachment style and psychopathological symptoms.

The specific association between the preoccupied style and symptoms allows for a better understanding of the meaning and purpose of certain internalizing and externalizing symptoms that are frequently related with an hiperactivation of the attachment system. This hiperactivation is used by the adolescent to obtain attention and support from his/her attachment figure and to guarantee his/her availability.

Given the prevalence of the preoccupied attachment style in the clinical participants and the association found between this style and symptoms, future studies could elucidate whether the assessment of attachment in adolescence is useful for planning psychotherapy or for evaluating its results, in the same way it has been shown to be useful for adult population (Daniel, 2006; Levy, Ellison, Scott, \& Bernecker, 2011; Slade, 2008).

\section{Limitations}

This study examined the relationship between the three attachment styles and psychopathological symptoms; however, it did not include disorganized attachment, which is the type of attachment that is related most closely to psychopathology at all ages (Bakermans-Kranenburg \& Van Ijzendoorn, 2009; DeKlyen \& Greenberg, 2008; Dozier, StovallMcClough, \& Albus, 2008). This limitation was due to the use of the CaMir Q-sort questionnaire to assess attachment, given that disorganized attachment cannot be assessed using a questionnaire.

Although the use of questionnaires is the most commonly utilized method to evaluate attachment and symptoms in adolescents, the associations between attachment and symptoms may be inflated, as this method shares a common source and variance (Brumariu \& Kerns, 2010; Colonnesi et al., 2011). Studies that employ other evaluation methods are necessary to avoid the bias that is produced by shared variance.

The study was also limited in that the psychopathological symptoms were assessed using a single self-report measure. In particular, with respect to assessing behavior problems, the use of additional external respondents would be benefi- 
cial, as the use of self-report measures to assess these behaviors in adolescents can affect the validity of the measurements. Although the YSR has adequate psychometric properties, future studies should employ complementary questionnaires to provide data from additional perspectives.

Another limitation involved the cross-sectional design of the study. Although insecure attachment is believed to in-

\section{References}

Abad, J., Forns, M., \& Gómez, J. (2002). Emotional and behavioral problems as mesured by the YSR: Gender and age differences in spain adolescents. European Journal of Psychological Assessment, 18(2), 149-157. Doi: 10.1027//1015-5759.18.2.157

Achenbach, T. M. (1991). Manual for the Youth Self Report and 1991 Profile. Burlington, VT: Dept. of Psychiatry, University of Vermont.

Adam, K. S., Sheldon-Keller, A. E., \& West, M. (1996). Attachment organization and history of suicidal behavior in clinical adolescents. Journal of Consulting and Clinical Psychology, 64(2), 264-272. Doi: 10.1037/0022006X.64.2.264

Allen, J. P. (2008). Attachment system in adolescence. In J. Cassidy, \& P. R. Shaver (Eds.), Handbook of Attachment: Theory, Research and Clinical Applications (pp. 419-435). New York, London: The Guilford Press.

Allen, J. P., Hauser, S. T., \& Borman-Spurrell, E. (1996). Attachment theory as a framework for understanding sequelae of severe adolescent psychopathology: An 11-year follow-up study. Journal of Consulting and Clinical Psychology, 64(2), 254-263. Doi: 10.1037/0022-006X.64.2.254

Allen, J. P., Insabella, G., Porter, M. R., Smith, F. D., Land, D., \& Phillips, N. (2006). A social-interactional model of the development of depressive symptoms in adolescence. Journal of Consulting and Clinical Psychology, 74(1), 55-65. Doi: 10.1037/0022-006X.74.1.55

Allen, J. P., Marsh, P., McFarland, C., McElhaney, K. B., Land, D. J., Jodl, K. M., \& Peck, S. (2002). Attachment and autonomy as predictors of the development of social skills and delinquency during midadolescence. Journal of Consulting and Clinical Psychology, 70(1), 56-66. Doi: 10.1037/0022-006X.70.1.56

Allen, J. P., Moore, C., Kuperminc, G., \& Bell, K. (1998). Attachment and adolescent psychosocial functioning. Child Development, 69(5), 14061419. Doi: $10.1111 /$ j.1467-8624.1998.tb06220.x

Bakermans-Kranenburg, M. J., \& Van Ijzendoorn, M. H. (2009). The first 10,000 adult attachment interviews: Distributions of adult attachment representations in clinical and non-clinical groups. Attachment and Human Development, 11(3), 223-263. Doi: 10.1080/14616730902814762

Benony, H., Peny, L., Gianoli, M., Hernandez, S., \& Larome, A. (2001). Étude descriptive des modèles individuels de relations chez des patients psychotiques débutants. Annales Médico-Psychologiques, 159, 589-594. Doi: 10.1016/S0003-4487(01)00097-X

Brown, L. S., \& Wright, J. (2003). The relationship between attachment strategies and psychopathology in adolescence. Psychology and Psychotherapy: Theory Research and Practice, 76(4), 351-367. Doi: 10.1348/147608303770584728

Brumariu, L. E., \& Kerns, K. A. (2010). Parent-child attachment and internalizing symptoms in childhood and adolescence: A review of empirical findings and future directions. Development and Psychopathology, 22(1), 177203. Doi: 10.1017/S0954579409990344

Colonnesi, C., Draijer, E. M., Jan, J. M. S., Van der Bruggen, C. O., Bogels, S. M., \& Noom, M. J. (2011). The relation between insecure attachment and child anxiety: A meta-analytic review. Journal of Clinical Child and Adolescent Psychology, 40(4), 630-645. Doi: 10.1080/15374416.2011.581623

Daniel, S. I. (2006). Adult attachment patterns and individual psychotherapy: A review. Clinical Psychology Review, 26(8), 968-984. Doi: 10.1016/j.cpr.2006.02.001

DeKlyen, M., \& Greenberg, M. T. (2008). Attachment and psychopathology in childhood. In J. Cassidy, \& P. R. Shaver (Eds.), Handbook of Attachment: Theory, Research and Clinical Applications (pp. 637-665). New York: The Guilford Press. crease an individual's vulnerability to psychopathology, other intervening factors might explain the relationship between attachment and psychopathology, or the psychopathological problems of adolescents might be the source of relationship problems with primary caregivers. Future research that incorporates a longitudinal design should address these issues.

Doyle, A. B., \& Markiewicz, D. (2005). Parenting, marital conflict and adjustment from early- to mid-adolescence: Mediated by adolescent attachment style? Journal of Youth and Adolescence, 34(2), 97-110. Doi: 10.1007/s10964-005-3209-7

Dozier, M. (1990). Attachment organization and treatment use for adults with serious psychopathological disorders. Development and Psychopathology, 2(1), 47-60. Doi: 10.1017/S0954579400000584

Dozier, M., \& Lee, S. W. (1995). Discrepancies between self- and otherreport of psychiatric symptomatology: Effects of dismissing attachment strategies. Development and Psychopathology, 7(1), 217-226. Doi: 10.1017/S095457940000643X

Dozier, M., Stovall-McClough, K. C., \& Albus, K. E. (2008). Attachment and psychopathology in adulthood. In J. Cassidy, \& P. R. Shaver (Eds.), Handbook of Attachment: Theory, Research and Clinical Applications (pp. 718744). New York: The Guilford Press.

Hankin, B. L. (2005). Childhood maltreatment and psychopathology: Prospective test of attachment, cognitive vulnerability, and stress as mediating processes. Cognitive Therapy and Research, 29(6), 645-671. Doi: 10.1007/s10608-005-3166-1

Kobak, R. R., Cole, H. E., Ferenz-Gillies, R., Fleming, W. S., \& Gamble, W. (1993). Attachment and emotion regulation during mother-teen problem solving: A control theory analysis. Child Development, 64(1), 231-245. Doi: 10.1111/j.1467-8624.1993.tb02906.x

Kobak, R. R., Sudler, N., \& Gamble, W. (1991). Attachment and depressive symptoms during adolescence: A developmental pathways analysis. Development and Psychopathology, 3(4), 461-474. Doi: 10.1017/S095457940000763X

Lacasa, F. (2008). Relación entre el vínculo afectivo, psicopatología y cambio, en una muestra de adolescentes. Estudio comparativo entre una muestra clinica que han realizado psicoterapia de grupo y una muestra comunitaria. (Unpublished doctoral dissertation). Barcelona: Department of Psychology, University Autonomous of Barcelona.

Lemos, S., Vallejo, G., \& Sandoval, M. (2002). Estructura factorial del youth self report (YSR). Psicothema, 14(4), 816-822. Retrieved from http://www.psicothema.com/psicothema.asp?ID=804

Levy, K. N., Ellison, W. D., Scott, L. N., \& Bernecker, S. L. (2011). Attachment style. Journal of Clinical Psychology, 67(2), 193-203. Doi: 10.1002/jclp.20756/

Mikulincer, M., \& Shaver, P. R. (2007). Attachment bases of psychopathology. Attachment in adulthood. Structure, Dynamics, and Change (pp. 369-404). New York: The Guilford Press.

Milikovitch, R., Pierrehumbert, B., Karmaniola, A., Bader, M., \& Halfon, O. (2005). Assessing attachment cognitions and their associations with depression in youth with eating or drug misuse disorders. Substance Use and Misuse, 40(5), 605-623. Doi: 10.1081/JA-200055349

Muela, A., Torres, B., \& Balluerka, N. (2012). Estilos de apego y psicopatología en adolescentes víctimas de maltrato infantil. Infancia y Aprendizaje, 35(4), 451-469. Doi: 10.1174/021037012803495294

Muela, A. (2011). Desprotección infantil, estilos de apego e indicadores de psicopatología en la adolescencia. Bilbao: Department of Psychology, University of the Basque Country.

Muris, P., Meesters, C., Morren, M., \& Moorman, L. (2004). Anger and hostility in adolescents: relationships with self-reported attachment style and perceived parental rearing styles. Journal of Psychosomatic Research, 57(3), 257-264. Doi: 10.1016/S0022-3999(03)00616-0 
Muris, P., Mayer, B., \& Meesters, C. (2000). Self-reported attachment style, anxiety, and depression in children. Social Behavior and Personality: An International Journal, 28(2), 157-162. Doi: 10.2224/sbp.2000.28.2.157

Muris, P., \& Meesters, C. (2002). Attachment, behavioral inhibition, and anxiety disorders symptoms in normal adolescents. Journal of Psychopathology and Behavioral Assessment, 24(2), 97-106. Doi: 10.1023/A:1015388724539

Muris, P., Meesters, C., van Melick, M., \& Zwambag, L. (2001). Selfreported attachment style, attachment quality, and symptoms of anxiety and depression in young adolescents. Personality and Individual Differences, 30(5), 809-818. Doi: 10.1016/S0191-8869(00)00074-X

Muris, P., Meesters, C., \& van der Berg, S. (2003). Internalizing and externalizing problems as correlates of self-report attachment style and perceived rearing in normal adolescents. Journal of Child and Family Studies, 12(2), 171-183. Doi: 10.1023/A:1022858715598

Nishikawa, S., Hägglöf, B., \& Sundbom, E. (2010). Contributions of attachment and self-concept on internalizing and externalizing problems among japanese adolescents. Journal of Child and Family Studies, 19(3), 334-342. Doi: 10.1007/s10826-009-9303-9

Pierrehumbert, B., Karmaniola, A., Sieye, A., Meister, C., Miljkovitch, R., \& Alfon, O. (1996). Les modèles de relations: Développement d'un autoquestionnaire d'attachement pour adultes. Psychiatrie de l'Enfant, 39(1), 161-206. Retrieved

from http://bsf.spp.asso.fr/index.php?lvl=notice display\&id $=43650$

Pierrehumbert, B., Bader, M., Miljkovitch, R., Mazet, P., Amar, M., \& Halfon, O. (2002). Strategies of emotion regulation in adolescents and young adults with substance dependence o eating disorders. Clinical Psychology and Psychotherapy, 9(6), 384-394. Doi: 10.1002/cpp.339

Ronnlund, M., \& Karlsson, E. (2006). The relation between dimensions of attachment and internalizing or externalizing problems during adoles- cence. The Journal of Genetic Psychology, 167(1), 47-63. Doi: 10.3200/GNTP.167.1.47-63

Rosenstein, D. S., \& Horowitz, H. A. (1996). Adolescent attachment and psychopathology. Journal of Consulting and Clinical Psychology, 64(2), 244 253. Doi: 10.1037/0022-006X.64.2.244

Sandoval, M., Lemos, S., \& Vallejo, G. (2006). Self-reported competences and problems in spanish adolescents: A normative study of the YSR. Psicothema, 18(4), 804-809. Retrieved from http://www.psicothema.com/psicothema.asp?ID=3312

Shaver, P. R., \& Mikulincer, M. (2002). Attachment-related psychodynamics. Attachment and Human Development, 4(2), 133-161. Doi: $10.1080 / 14616730210154171$

Slade, A. (2008). The implications of attachment theory and research for adult psychotherapy. In J. Cassidy, \& P. R. Shaver (Eds.), Handbook of Attachment: Theory, Research and Clinical Applications (pp. 762-782). New York, London: The Guilford Press.

Wallis, P., \& Steele, H. (2001). Attachment representations in adolescence: Further evidence from psychiatric residential settings. Attachment and Human Development, 3(3), 259-268. Doi: 10.1080/14616730110096870

Ward, M. J., Lee, S. S., \& Polan, H. J. (2006). Attachment and psychopathology in a community sample. Attachment and Human Development, 8(4), 327-340. Doi: 10.1080/14616730601048241

Zubeidat, I., Fernández, A., Ortega, J. E., Vallejo, M. A., \& Sierra, J. C. (2009). Características psicosociales y psicopatológicas en una muestra de adolescentes españoles a partir del "Youth Self-Report"/11-18. Anales de Psicología, 25(1), 60-69.

(Article received: 26-02-2013; revised: 10-12-2013; accepted: 05-04-2014) 